University of Wollongong

Research Online

Faculty of Engineering and Information

Faculty of Engineering and Information

Sciences - Papers: Part A

Sciences

$1-1-2016$

\title{
Microstructure and mechanical properties of strip cast TRIP steel subjected to thermo-mechanical simulation
}

\author{
Zhiping Xiong \\ University of Wollongong, zx868@uowmail.edu.au \\ Andrii Kostryzhev \\ University of Wollongong, andrii@uow.edu.au \\ Liang Chen \\ University of Wollongong, Ichen@uow.edu.au \\ Elena V. Pereloma \\ University of Wollongong, elenap@uow.edu.au
}

Follow this and additional works at: https://ro.uow.edu.au/eispapers

Part of the Engineering Commons, and the Science and Technology Studies Commons

Research Online is the open access institutional repository for the University of Wollongong. For further information contact the UOW Library: research-pubs@uow.edu.au 


\title{
Microstructure and mechanical properties of strip cast TRIP steel subjected to thermo-mechanical simulation
}

\begin{abstract}
Instead of hot rolling and cold rolling followed by annealing, strip casting is a more economic and environmentally friendly way to produce transformation-induced plasticity (TRIP) steels. According to industrial practice of strip casting, rapid cooling in this work was achieved using a dip tester, and a Gleeble 3500 thermo-mechanical simulator was used to carry out the processing route. A typical microstructure of TRIP steels, which included $\sim 0.55$ fraction of polygonal ferrite with bainite, retained austenite and martensite, was obtained. The effects of deformation ( 0.41 reduction) above nonrecrystallisation temperature, isothermal bainite transformation temperature and the size of second phase region on microstructure and mechanical properties were studied. The steel isothermally transformed at $400{ }^{\circ} \mathrm{C}$ had the best combination of ultimate tensile strength (UTS) and total elongation (TE), whether deformation was applied or not. The deformation resulted in the improvement of mechanical properties after holding at $400{ }^{\circ} \mathrm{C}$ : the UTS increased from 590 to $696 \mathrm{MPa}$ and TE decreased from 0.27 only to 0.26 . It was predominantly ascribed to grain size refinement and dislocation strengthening. The studied TRIP steel had comparable mechanical properties with TRIP 690 produced commercially.
\end{abstract}

\section{Keywords}

trip, microstructure, steel, mechanical, subjected, thermo, simulation, properties, strip, cast

\author{
Disciplines \\ Engineering | Science and Technology Studies
}

\section{Publication Details}

Xiong, Z. P., Kostryzhev, A. G., Chen, L. \& Pereloma, E. V. (2016). Microstructure and mechanical properties of strip cast TRIP steel subjected to thermo-mechanical simulation. Materials Science and Engineering A: Structural Materials: Properties, Microstructure and Processing, 677 356-366. 


\title{
Microstructure and mechanical properties of strip cast TRIP steel subjected to thermo-mechanical simulation
}

\author{
Z.P. Xiong ${ }^{1 *}$, A.G. Kostryzhev ${ }^{1}$, L. Chen ${ }^{1}$, E.V. Pereloma ${ }^{1,2}$ \\ ${ }^{1}$ School of Mechanical, Materials and Mechatronic Engineering, University of Wollongong, \\ Wollongong, NSW 2522, Australia \\ ${ }^{2}$ Electron Microscopy Centre, University of Wollongong, Wollongong, NSW 2519, Australia
}

\begin{abstract}
Instead of hot rolling and cold rolling followed by annealing, strip casting is a more economic and environmentally friendly way to produce transformation-induced plasticity (TRIP) steels. According to industrial practice of strip casting, rapid cooling in this work was achieved using a dip tester, and a Gleeble 3500 thermo-mechanical simulator was used to carry out the processing route. A typical microstructure of TRIP steels, which included $\sim 0.55$ fraction of polygonal ferrite with bainite, retained austenite and martensite, was obtained. The effects of deformation ( 0.41 reduction) above non-recrystallisation temperature, isothermal bainite transformation temperature and the size of second phase region on microstructure and mechanical properties were studied. The steel isothermally transformed at $400{ }^{\circ} \mathrm{C}$ had the best combination of ultimate tensile strength (UTS) and total elongation (TE), whether deformation was applied or not. The deformation resulted in the improvement of mechanical properties after holding at $400{ }^{\circ} \mathrm{C}$ : the UTS increased from 590 to $696 \mathrm{MPa}$ and TE decreased from 0.27 only to 0.26 . It was predominantly ascribed to grain size refinement and dislocation strengthening. The studied TRIP steel had comparable mechanical properties with TRIP 690 produced commercially.
\end{abstract}

Keywords: TRIP steel; Strip casting; Thermo-mechanical processing; Mechanical properties; Carbon diffusion; Isothermal bainite transformation.

*Correspondence author email address: zx868@uowmail.edu.au (Z.P. Xiong) 


\section{Introduction}

The development of advanced high strength steels (AHSSs) for the automotive industry is driven by the request for weight reduction in order to improve the fuel economy $[1,2]$. Lowalloyed transformation-induced plasticity (TRIP) assisted steels are good AHSS candidates due to their excellent ductility combined with high strength. TRIP steels have a multi-phase microstructure, including polygonal ferrite, bainite, martensite and retained austenite (RA) [3-9]. In fact, the key characteristic of these steels is the presence of stabilised austenite at room temperature $[4,6,10,11]$. This stabilised austenite can transform to martensite during deformation, which contributes to an increase in ductility. The stability of RA is mainly controlled through its carbon content and morphology, which offers a chance to tune the microstructure through thermo-mechanical processing $[4,10]$. The processing schedules contain two important stages $[12,13]$. The first stage is to form polygonal ferrite via cooling through or holding for a certain time in the austenite-ferrite temperature region. The polygonal ferrite provides ductility in this steel and leads to the carbon enrichment of austenite; the austenite enriched with carbon is stable against martensitic transformation during rapid cooling to isothermal bainite transformation (IBT) temperature [1, 12-14]. The second stage is to form carbide-free bainite during holding at bainite formation temperature following rapid cooling from the austenite-ferrite temperature region. At this stage, the austenite is further enriched with carbon, which results in the RA preserved at room temperature $[1,12-14]$.

The strip casting aims to directly produce strip steels from liquid metals [15]. Compared to hot and cold rolling, the strip casting eliminates many procedures, such as rough rolling and reheating, resulting in a decrease in gas emission, energy consumption and operation cost [15]. However, the large prior austenite grain size (PAGS) (approximately $100-200 \mu \mathrm{m}$ ) complicates tuning of the microstructure via the adjustment of heat treatment parameters $[15$, 16]. It is well known that the PAGS dictates the final microstructure of the transformation products at room temperature such that refining the former leads to a fine grain size of the latter [17-19]. For example, Cota et. al. reported that the average ferrite gain size increased from 8 to $\sim 40 \mu \mathrm{m}$ when the PAGS increased from 9.5 to $100 \mu \mathrm{m}$ [18]. In addition, PAGS also affects the bainite transformation in such a way that a coarser PAGS leads to larger bainite packet size and a decrease in bainite transformation rate [20-22].

At present, carbon steels, silicon steels and stainless steels are manufactured in industry by the strip casting technology [23, 24]. Daamen et. al. reported a trial to obtain twinninginduced plasticity (TWIP) steels using this technology in the laboratory [25]. The dual phase steels were obtained by the present authors via the simulation of strip casting [26, 27]. For TRIP steels, researchers focus on further development of hot rolling and cold rolling followed by annealing. Except our previous paper, which presented the microstructure and mechanical properties of TRIP steels obtained via the simulation of strip casting without deformation [28], there is no other published study on the production of TRIP steels using strip casting technology. This paper presents a further step in our investigation, namely the effect of austenite deformation on the microstructure and mechanical properties. With an increase in the amount of deformation the microstructure was refined and the mechanical properties were 
enhanced. The strengthening mechanisms responsible for the properties improvement were analysed; in particular, the effect of second phase region size on RA retention was discussed based on the carbon distribution.

\section{Experimental Detail}

The chemical composition of studied steel mainly consisted of $0.172 \mathrm{C}, 1.520 \mathrm{Si}, 1.610 \mathrm{Mn}$, $0.0266 \mathrm{Al}, 0.0153 \mathrm{Cu}, 0.195 \mathrm{Cr}$ and balance $\mathrm{Fe}$ (all in wt. \%). It was similar to the chemical composition of conventional TRIP steels $[1,2]$. As-cast specimens of $36 \times 36 \mathrm{~mm}^{2}$ and 1.2 $\mathrm{mm}$ thickness were produced at Deakin University using a dip tester [29]. The dip tester was designed to simulate the initial contact conditions of a twin roll caster used in strip casting technology $[25,30]$. The copper substrates spot welded with R-type thermocouple were used as contact surfaces between liquid metals and twin rollers, which was immersed into the molten metal for a certain time in order to achieve different high cooling rates of up to $\sim 1700$ $\mathrm{Ks}^{-1}[25,31]$ characteristic for the strip casting process. Then the copper substrates were removed from the furnace and the solidified samples were then used in this study.

The thermo-mechanical schedule illustrated in Fig. 1 was carried out on a Gleeble 3500 thermo-mechanical simulator in hydrawedge mode. Samples of 20 x 15 x $(0.9-1.2) \mathrm{mm}^{3}$ were cut from the as-cast samples. Because of the small thickness beyond the movement control capability of the Gleeble 3500 simulator, a sandwiched sample was designed [26]. The studied sample spot welded with a K-type thermocouple was clamped by two dummy samples ( $2.5 \mathrm{~mm}$ thick; made of structural microalloyed steel). The sandwiched samples were heated at $40 \mathrm{Ks}^{-1}$ to $1000{ }^{\circ} \mathrm{C}$, then at $20 \mathrm{Ks}^{-1}$ to $1250{ }^{\circ} \mathrm{C}$ in order to avoid overshooting and held for $300 \mathrm{~s}$. This was followed by the cooling at $30 \mathrm{Ks}^{-1}$ to $1050{ }^{\circ} \mathrm{C}$, where the reduction $(\Delta=0.41 \pm 0.02)$ was applied at a strain rate of $0.5 \mathrm{~s}^{-1}$ and then by cooling at $10 \mathrm{Ks}^{-1}$ to the interrupted cooling temperature $\left(T_{I C}=670,690\right.$ and $\left.710^{\circ} \mathrm{C}\right)$. After this, the samples were cooled at $50 \mathrm{Ks}^{-1}$ to the IBT temperature $\left(T_{I B T}=350,400,450\right.$ and $\left.500{ }^{\circ} \mathrm{C}\right)$ and held for $900 \mathrm{~s}$ in order to provide time for bainite transformation. Finally, the samples were water quenched to room temperature. Some samples were directly water quenched from different $T_{I C}$ to room temperature in order to study the effect of $T_{I C}$ on ferrite formation. Holding at $1250{ }^{\circ} \mathrm{C}$ for $300 \mathrm{~s}$ was determined in order to simulate the prior austenite grain structure (the average grain size of $83 \pm 31 \mu \mathrm{m}$ ) inherent for strip casting, as described in the previous study [28]. 


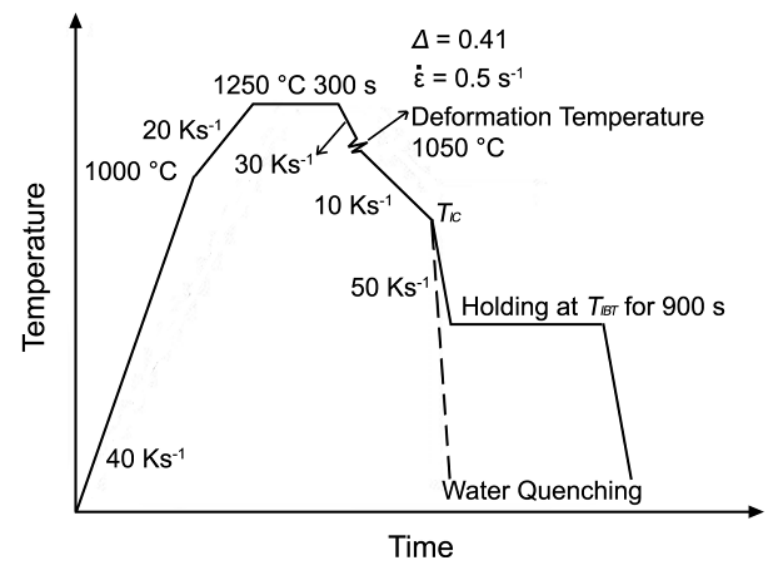

Figure 1. The thermo-mechanical schedule to produce the microstructure of TRIP steels.

Plain strain compression during hot rolling was simulated in the thermo-mechanical experiments. Thus, the coordinate of normal direction (ND), rolling direction (RD) and transverse direction (TD) is used in this study. The deformed samples were cut parallel to the RD-ND plane, and then were hot mounted, mechanically polished and etched using 2 vol. \% nital for optical microscopy $(\mathrm{OM})$ and scanning electron imaging. The microstructures were characterised using a Leica optical microscope (OM) and a JEOL JSM-7001F field emission gun - scanning electron microscope (FEG - SEM) operating at $15 \mathrm{kV}$. All micrographs were taken from the centre of samples' cross-section. The fractions of ferrite and second phase region were calculated based on the variation in grey scales in the optical micrographs using Photoshop and Image Pro-Plus software. At least 260 ferrite grains or second phase regions were used to calculate the equivalent circle diameter. It is noted that the RA fraction could not be measured in the present study using X-ray diffraction due to small sample width $(\sim 2.5$ $\mathrm{mm}$ ) after deformation.

Simultaneous electron backscattering diffraction (EBSD) and energy dispersive X-ray spectroscopy (EDS) mapping was undertaken on the same JEOL JSM-7001F FEG - SEM operating at $15 \mathrm{kV}$ accelerating voltage, $5 \mathrm{nA}$ probe current and fitted with a Nordlys-II(S) EBSD and an $80 \mathrm{~mm}^{2} \mathrm{X}$-Max EDS detectors interfacing with the Oxford Instruments Aztec software suite. The sample preparation included mechanical polishing up to $1 \mu \mathrm{m}$ followed by electropolishing using an electrolyte of $330 \mathrm{ml}$ methanol, $330 \mathrm{ml}$ butoxyethanol and $40 \mathrm{ml}$ perchloric acid at $50 \mathrm{~V}, \sim 1.0 \mathrm{~mA}$ and $17^{\circ} \mathrm{C}$ for $\sim 90 \mathrm{~s}$. EBSD-EDS mapping was conducted at the centre of the sample cross section using a step size of $0.04 \mu \mathrm{m}$. The discs for transmission electron microscopy (TEM) were cut parallel to the RD-TD plane using electrical discharge machine, polished to $80 \mu \mathrm{m}$ thickness using silicon papers, and twin-jet electropolished with an electrolyte containing $10 \mathrm{vol}$. \% perchloric acid in methanol. The JEOL 2011 TEM and JEOL JEM-ARM200F operating at $200 \mathrm{kV}$ were used to characterise the microstructures. 
The dog-bone shaped samples for tensile testing were cut through RD-TD plane; their gauge length, width and thickness were 4.9, 2.1 and $\sim 0.6 \mathrm{~mm}$, respectively. The tensile tests were carried out using an in-house modified $5 \mathrm{kN}$ Kammrath and Weiss $\mathrm{GmbH}$ tensile stage at a constant crosshead speed of $2 \mu \mathrm{m} \mathrm{s}^{-1}$, corresponding to an initial strain rate of $4 \times 10^{-4} \mathrm{~s}^{-1}$. At least two samples were tested for each condition.

\section{Results}

\subsection{Effect of interrupted cooling temperatures on ferrite formation}

As shown in Fig. 2, the ferrite fraction increased from $0.52 \pm 0.03$ to $0.71 \pm 0.02$ with a decrease in $T_{I C}$ from 710 to $670{ }^{\circ} \mathrm{C}$ because the time for ferrite formation was extended. As expected, it was consistent with many published results $[32,33]$. The $T_{I C}=710{ }^{\circ} \mathrm{C}$ was chosen in the following experiments as this temperature assured formation of $\sim 0.5$ fraction of ferrite. TRIP steels with 0.5 ferrite fraction were demonstrated to have a good combination of mechanical properties $[34,35]$.

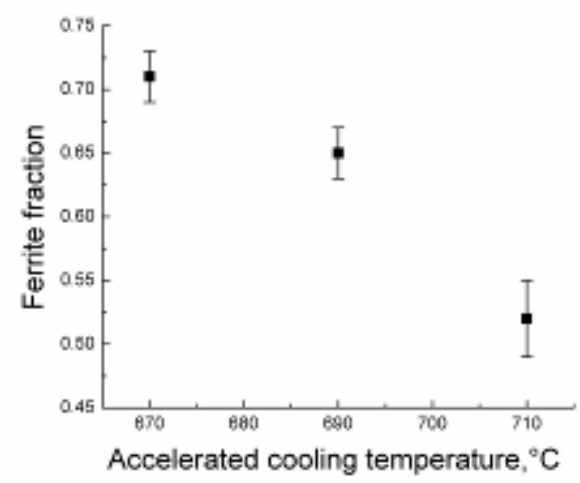

Figure 2. Effect of interrupted cooling temperature on ferrite fraction.

\subsection{Effect of isothermal bainite transformation temperature on microstructure evolution}

For comparison, the sample with a dual phase microstructure was produced by direct quenching from $710^{\circ} \mathrm{C}$ to room temperature (indicated via a dash line in Fig. 1) and referred to as TD Q in the following sections. It displayed the microstructure consisting of polygonal ferrite, second phase regions and a small amount of Widmänstatten ferrite (Fig. 3(a)). The second phase regions included martensite and some bainite (Fig. 3(b)). In addition, a layer of polygonal ferrite was observed near the sample surfaces (Fig. 3(a)). 

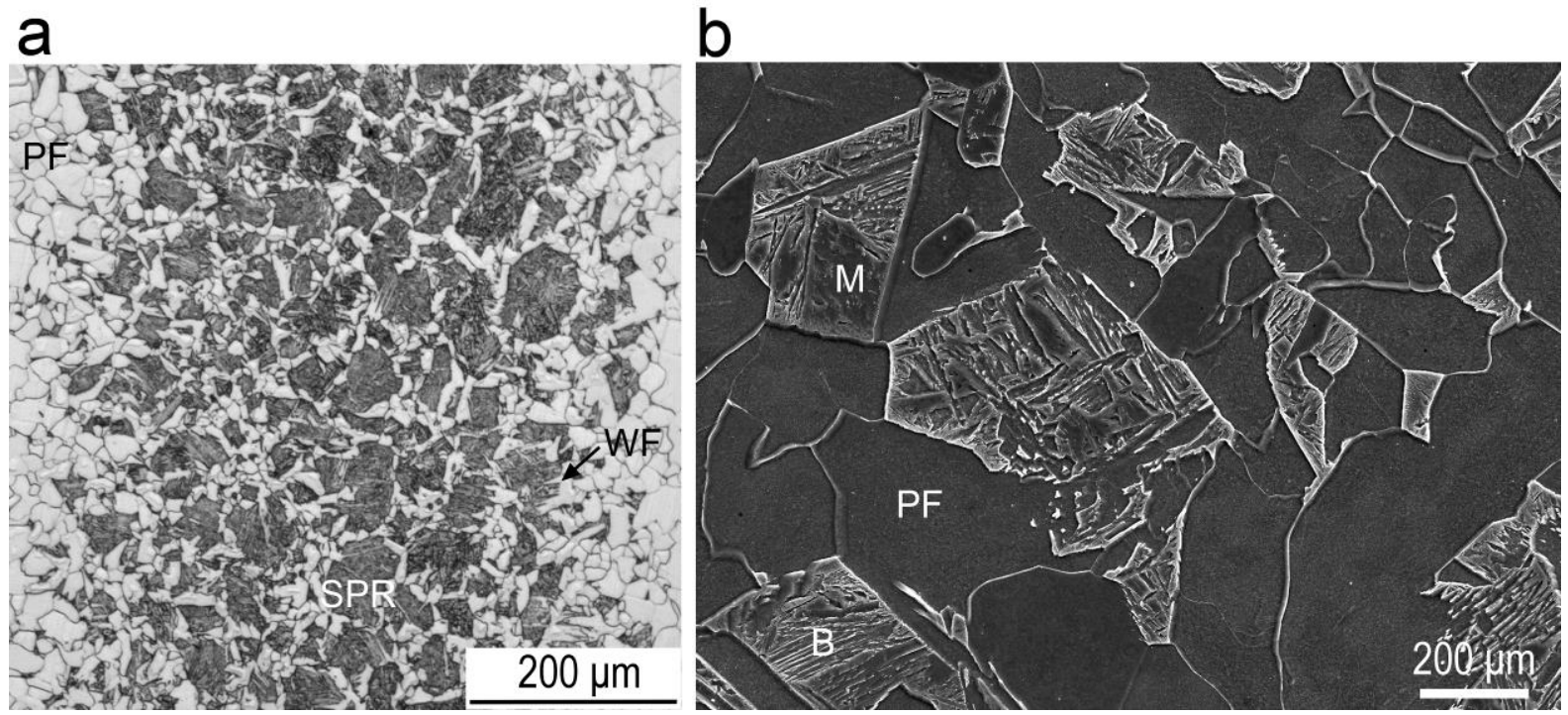

Figure 3. (a) Optical and (b) SEM images of the sample directly quenched from $710^{\circ} \mathrm{C}$. $P F$ is polygonal ferrite, $W F$ is Widmänstatten ferrite, $S P R$ is second phase region, $M$ is martensite and $B$ is bainite.

After fast cooling from the ferrite formation temperature $\left(710^{\circ} \mathrm{C}\right)$, the samples were held at $350,400,450$ and $500{ }^{\circ} \mathrm{C}$ for $900 \mathrm{~s}$. They were denoted as TD 350, TD 400, TD 450 and TD 500 , respectively. The optical microscopy of IBT samples showed a similar distribution of second phase regions to those in the TD Q sample (Fig. 3(a)). All the IBT samples had $\sim 0.55$ ferrite fraction.

After holding at $350{ }^{\circ} \mathrm{C}$ (TD 350), the microstructure consisted of polygonal ferrite, bainitic ferrite, granular bainite, martensite and RA in polygonal ferrite (Fig. 4). Bainitic ferrite consists of ferrite laths separated by film RA; whereas, granular bainite includes irregularshaped ferrite with dispersed blocky martensite and/or retained austenite (M/RA) constituent [36, 37]. Fig. 4(b) shows an example of a second phase region with a size of $\sim 1.2 \mu \mathrm{m}$ included bainitic ferrite. On the contrary, as an example, the M/RA island with a size of smaller than $1 \mu \mathrm{m}$ after quenching to room temperature was observed in Fig. 4(c). Fig. 5 (a) demonstrates film RA between bainitic ferrite laths in a small second phase region. Fig. 5 (b) shows one example of martensite island adjacent to the interface between polygonal ferrite and second phase region.
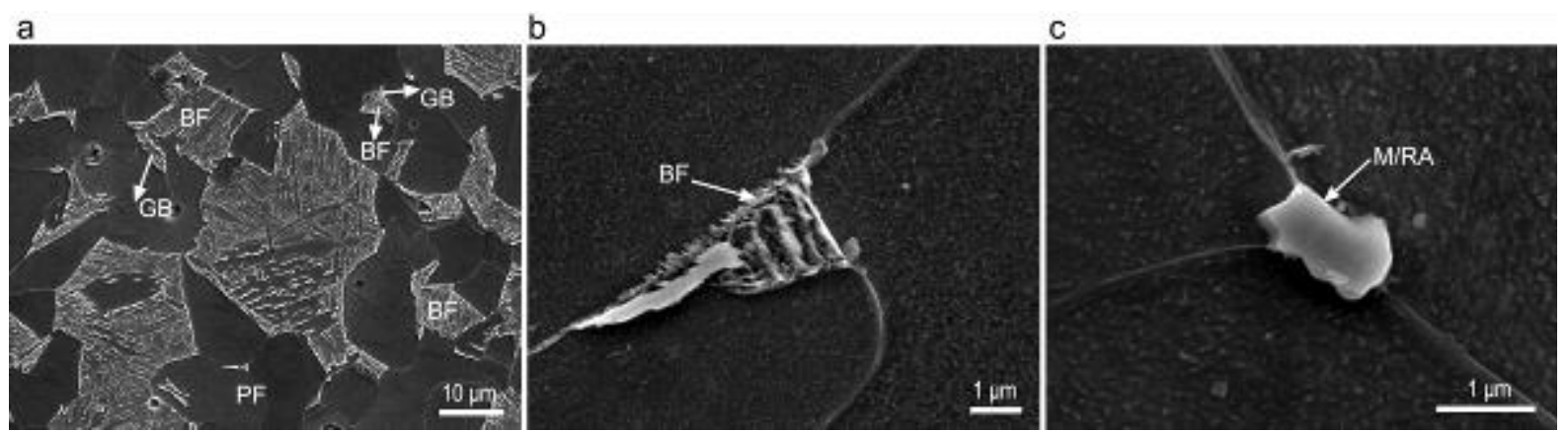

Figure 4. Selected SEM images of the sample after holding at $350{ }^{\circ} \mathrm{C}$ (TD 350): (a) overview; (b) bainitic ferrite; (c) martensite and/or retained austenite island. $P F$ is polygonal ferrite, $G B$ is granular bainite, $B F$ is bainitic ferrite and $M / R A$ is martensite and/or retained austenite. 
a

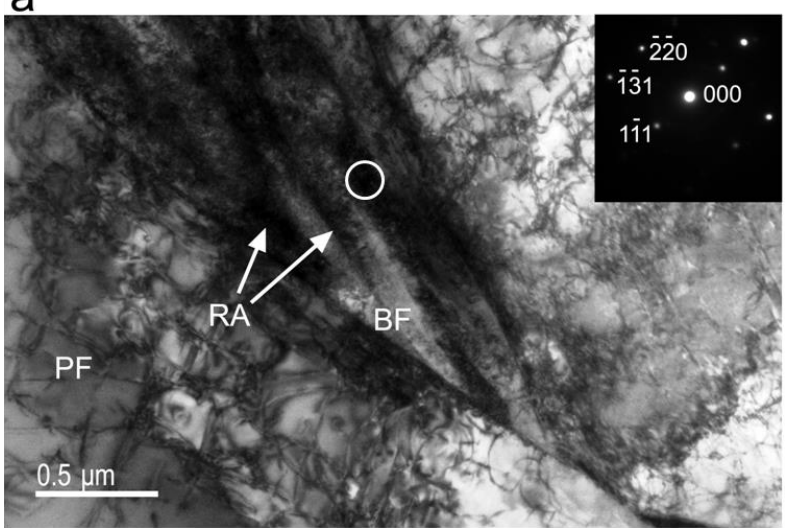

b

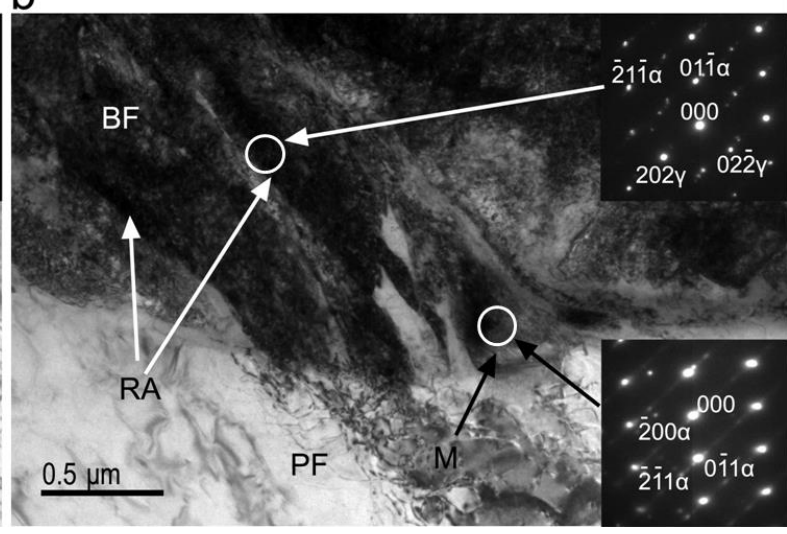

Figure 5. TEM images of TD 350 sample: (a) film retained austenite between bainitic ferrite laths in a small second phase region (the zone axis of inset is [112] $]_{\gamma}$ ); (b) martensite island adjacent to polygonal ferrite (the zone axis of insets is $[\overline{1} 11]_{\gamma}$ and $\left.[011]_{\alpha}\right) . P F$ is polygonal ferrite, $B F$ is bainitic ferrite, $M$ is martensite and $R A$ is retained austenite. Diffraction patterns were taken from circled areas.

With an increase in IBT temperature to $400{ }^{\circ} \mathrm{C}$ (TD 400), the phase balance in the TRIP steel was similar to that in the TD 350 sample, as shown in Fig. 6. In addition, a little amount of Widmänstatten ferrite was observed. Some small islands of granular bainite were observed (Fig. 6(b)). The M/RA islands with sizes smaller than $~ 3.5 \mu \mathrm{m}$ were preserved instead of transforming to bainite during the IBT holding (Fig. 6(b)). Some second phase regions shown in Fig. 6(c) included many bainite packets. The bright and dark field TEM imaging proved the presence of RA between the bainitic ferrite laths (Figs. 7(a, b)). On the other hand, the micrograph in Fig. 7(c) was taken from the centre of a large second phase region such that file RA was not observed between bainitic ferrite laths due to lower carbon content as discussed in Section 4.1.2. An example of a martensite island adjacent to the interface between the polygonal ferrite and the second phase region is also given in (Fig. 7(d)).
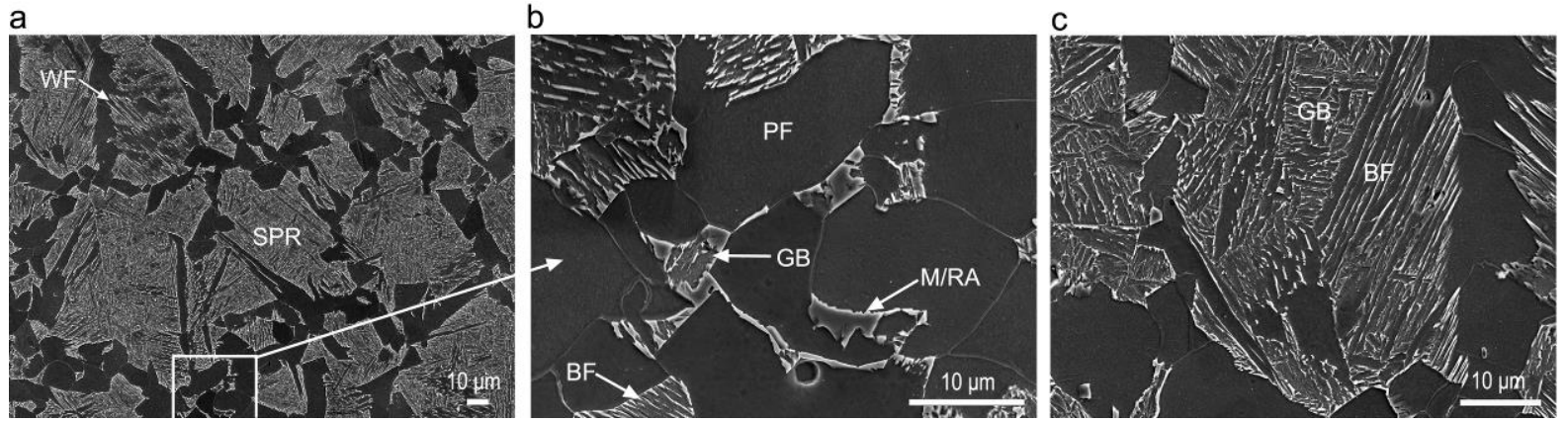

Figure 6. Selected SEM images of the sample after holding at $400{ }^{\circ} \mathrm{C}$ (TD 400): (a) overview; (b) small second phase regions; (c) large second phase regions. $S P R$ is second phase region, $P F$ is polygonal ferrite, $W F$ is Widmänstatten ferrite, $\mathrm{G} B$ is granular bainite, $B F$ is bainitic ferrite and $M / R A$ is martensite and/or retained austenite. 


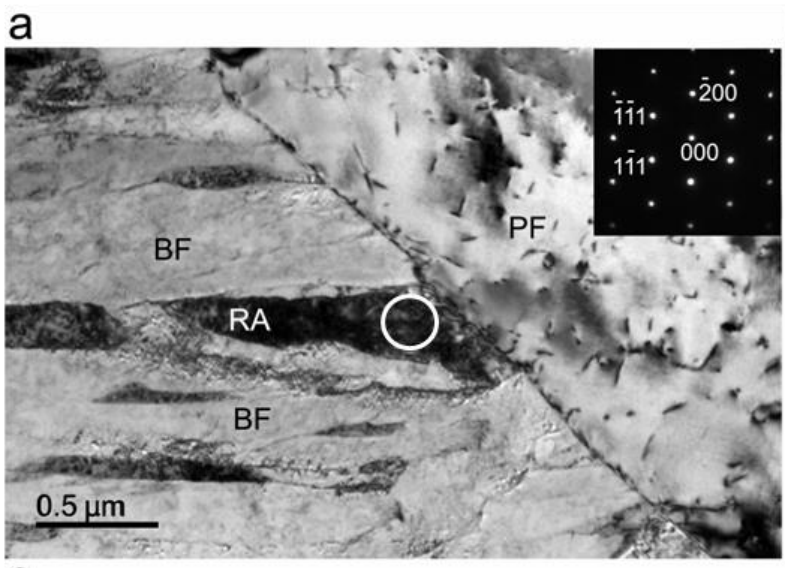

C

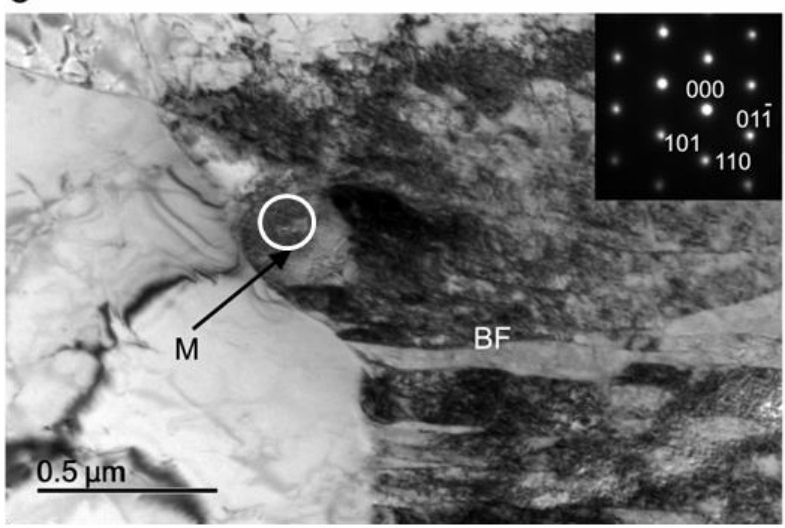

b

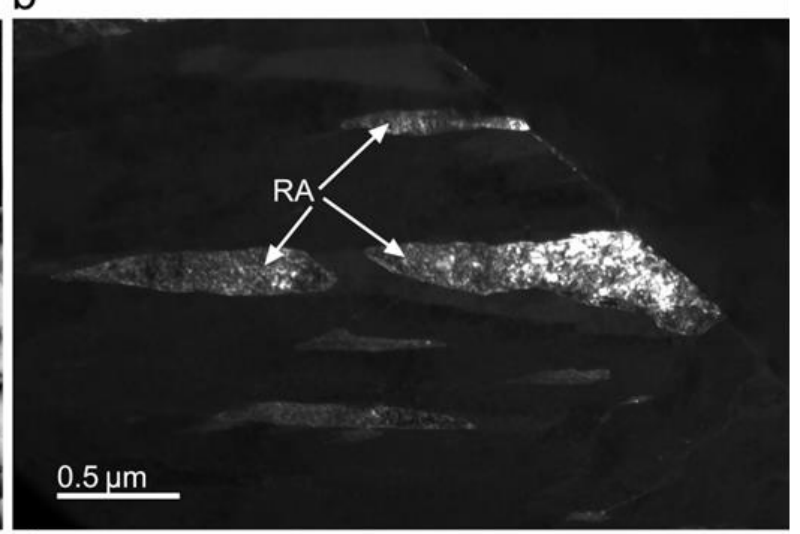

d

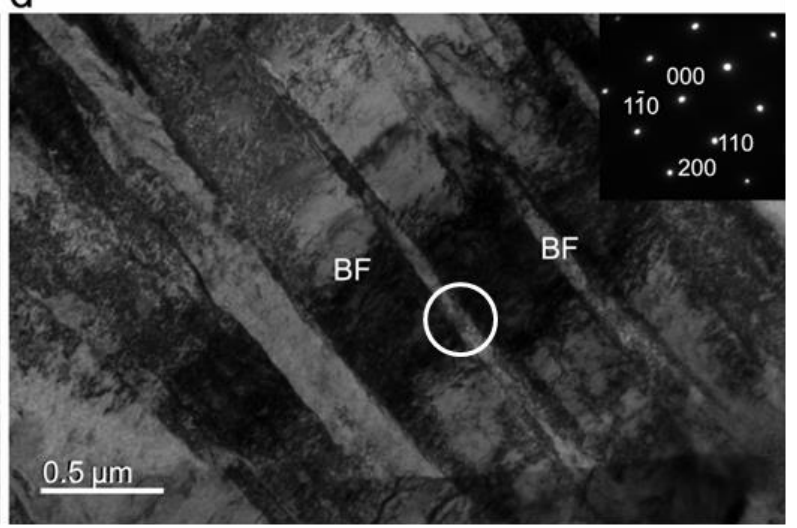

Figure 7. TEM images of TD 400 sample: (a) bright and (b) dark (from (200) $)_{\gamma}$ ) field images of retained austenite between bainitic ferrite laths (the zone axis of inset is $[011]_{\gamma}$ ); the zone axis of inset in (c, d) is $[\overline{1} 11]_{\alpha}$ and $[001]_{\alpha}$, respectively. $P F$ is polygonal ferrite, $B F$ is bainitic ferrite, $M$ is martensite and $R A$ is retained austenite. Diffraction patterns were taken from circled areas.

After holding at $450{ }^{\circ} \mathrm{C}$ (TD 400), the microstructure also consisted of polygonal ferrite, bainitic ferrite, granular bainite, and M/RA islands in polygonal ferrite (Fig. 8). Some second phase regions contained more of granular bainite than bainitic ferrite such as in Fig. 8(b). In addition, some coarse M/RA islands adjacent to bainitic ferrite were observed in the large second phase regions (Fig. 8(c)). Figs. 9 (a, b) show the RA and martensite formed near the interface between polygonal ferrite and second phase region. The observed twins in martensite, showed by arrows in Fig. 9 (b), indicate a relatively high carbon content, which is responsible for this twinned martensite. Several cementite particles between bainitic ferrite laths were observed via the selected area diffraction technique and dark field imaging (Figs. 9 (c, d)), indicating upper bainite formation. Similar formation of a limited upper bainite amount together with carbide-free bainite morphologies was reported in thermo-mechanically processed TRIP steel with IBT of $470{ }^{\circ} \mathrm{C}$ [38]. 

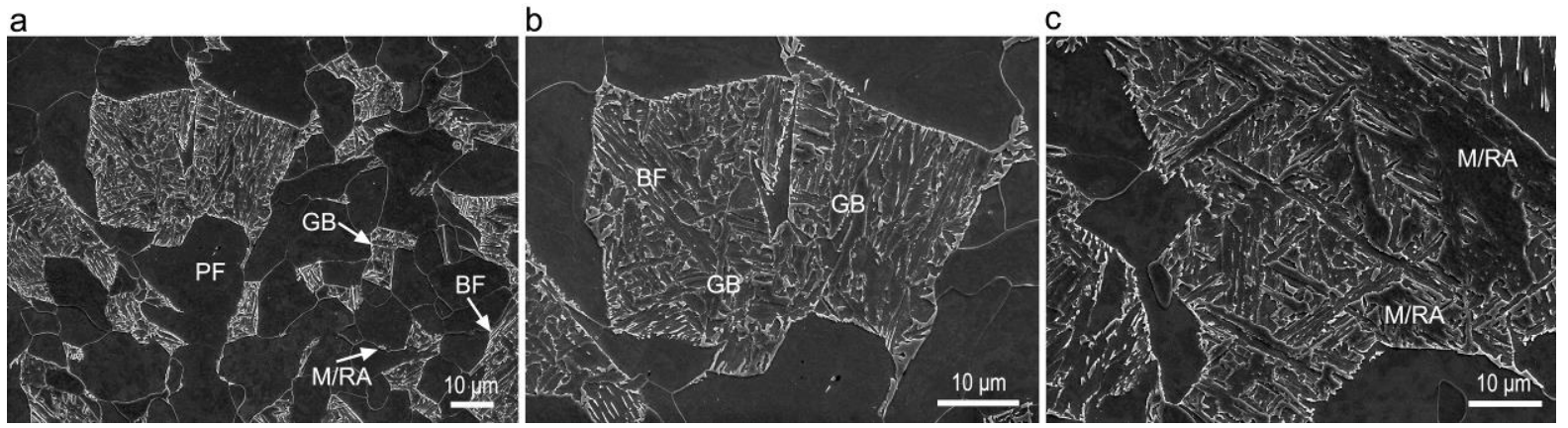

Figure 8. Selected SEM images of the sample after holding at $450{ }^{\circ} \mathrm{C}$ (TD 450). $P F$ is polygonal ferrite, GB is granular bainite, $B F$ is bainitic ferrite and $M / R A$ is martensite and/or retained austenite.
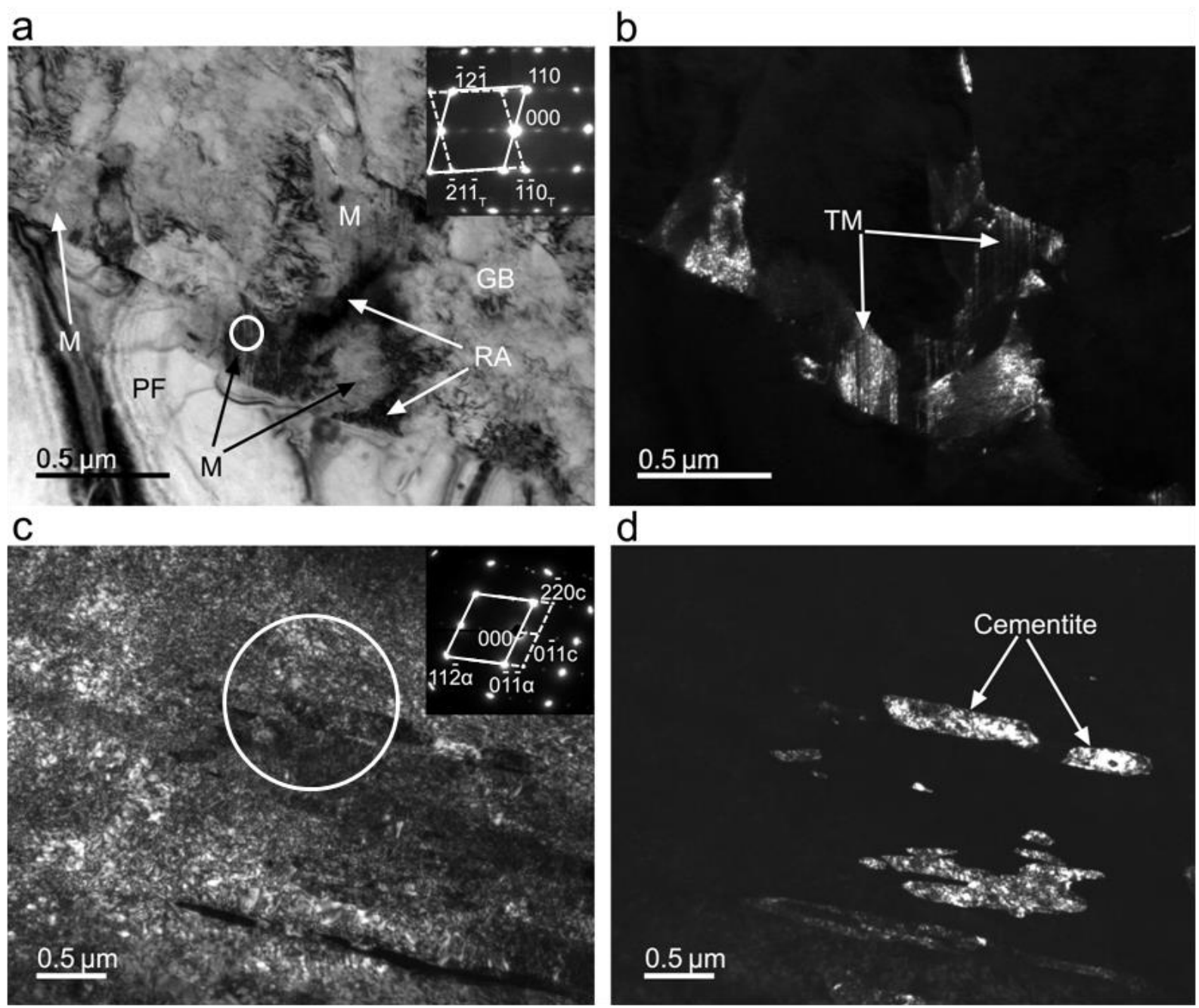

Figure 9. TEM images of TD 450 sample: (a) bright and (b) dark (from $(1 \overline{2} 1)_{\alpha}$ ) field images of martensite adjacent to the interface between polygonal ferrite and second phase region (the zone axis is near $[\overline{1} 13]_{\alpha}$ ); (c) bright and (d) dark (from $(0 \overline{1} 1)_{c}$ ) field images of cementite between bainitic ferrite laths (the zone axis of bainitic ferrite laths and cementite is near $[3 \overline{1} 1]_{\alpha}$ and $[111]_{c}$, respectively). $P F$ is polygonal ferrite, $G B$ is granular bainite, $M$ is martensite and $R A$ is retained austenite. Diffraction patterns were taken from circled areas. 
With a further increase in the IBT temperature to $500{ }^{\circ} \mathrm{C}$ (TD 500), the microstructure was changed significantly with appearance of many pearlite grains (Fig. 10). The pearlite formation is known to be harmful to the TRIP steel properties, due to the carbon consumption resulting in a decreased amount of RA [34, 39]. Thus, the further analysis of microstructure and measurements of mechanical properties for this condition were not carried out.
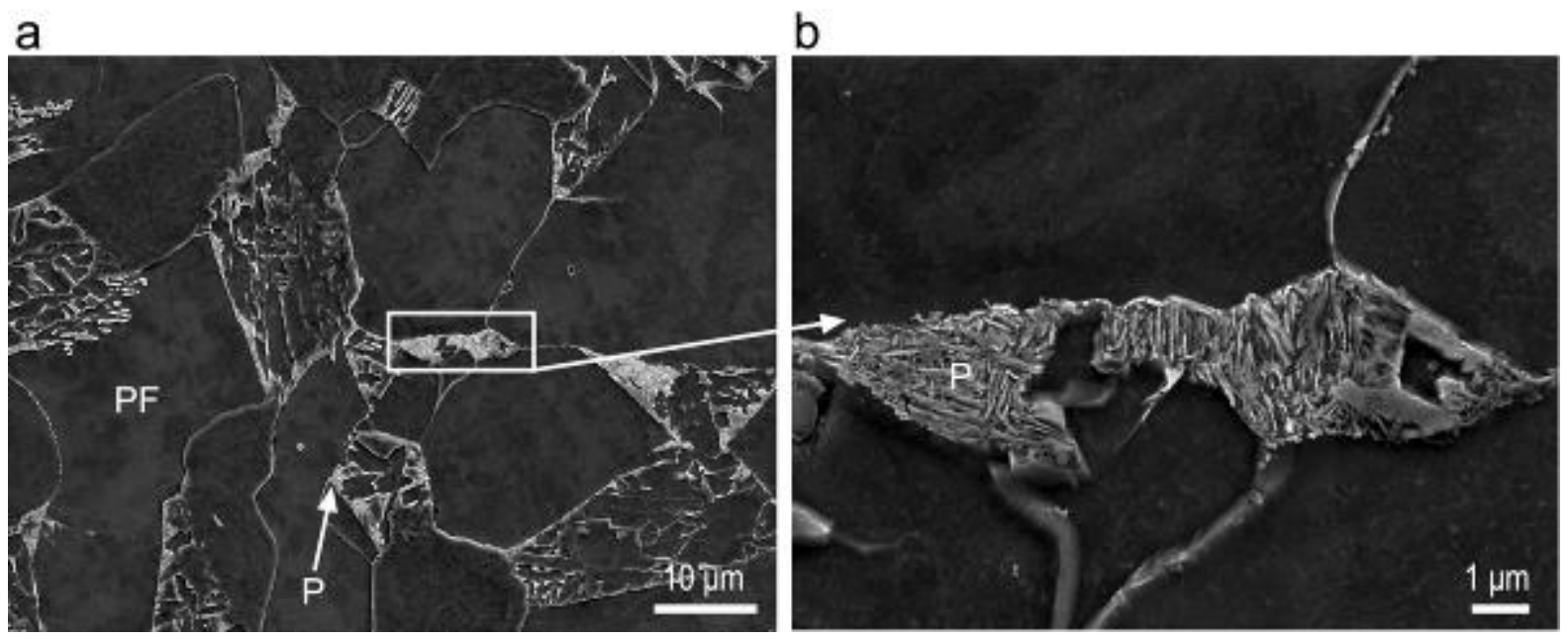

Figure 10. Selected SEM images of the sample after holding at $500{ }^{\circ} \mathrm{C}$ (TD 500). $P F$ is polygonal ferrite and $P$ is pearlite.

\subsection{Detailed characterisation of the TD 400 sample}

The distributions of ferrite grain size and the size of second phase region in TD 400 sample are shown as a representative in Fig. 11; the other samples (TD Q, TD 350, TD 400 and TD 450) had similar distributions due to the similar ferrite fraction. The distributions are of normal shape, i.e. they have a single maximum, however, a broaden one for the second phase regions. In TD 400 sample, the average grain size of ferrite was $13 \pm 7 \mu \mathrm{m}$ and the average size of second phase regions was $18 \pm 16 \mu \mathrm{m}$; the maximum sizes for ferrite and second phase regions were 48 and $95 \mu \mathrm{m}$, respectively.

In order to assess the deformation effect, three additional samples were produced in a dilatometer using the same austenitising and cooling schedule in Fig. 1, which, instead of deformation, contained a period of holding at $670{ }^{\circ} \mathrm{C}$ for $300 \mathrm{~s}$ in order to obtain 0.55 fraction of ferrite. These samples are denoted as T 350, T 400 and $\mathrm{T} 450$, corresponding to isothermal holding temperatures of 350,400 and $450{ }^{\circ} \mathrm{C}$, respectively. They are discussed in details elsewhere [28]. As shown in Table 1, deformation resulted in a decrease in the average ferrite grain size from $17 \pm 10$ to $13 \pm 7 \mu \mathrm{m}$ and the average size of second phase regions from $21 \pm 24$ to $18 \pm 16 \mu \mathrm{m}$, indicating a refined and more homogenised microstructure after deformation. 
a

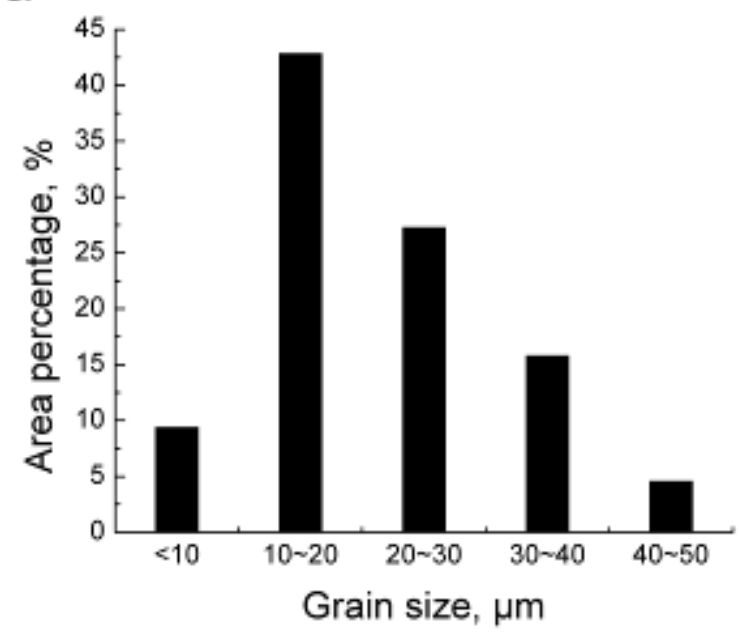

b

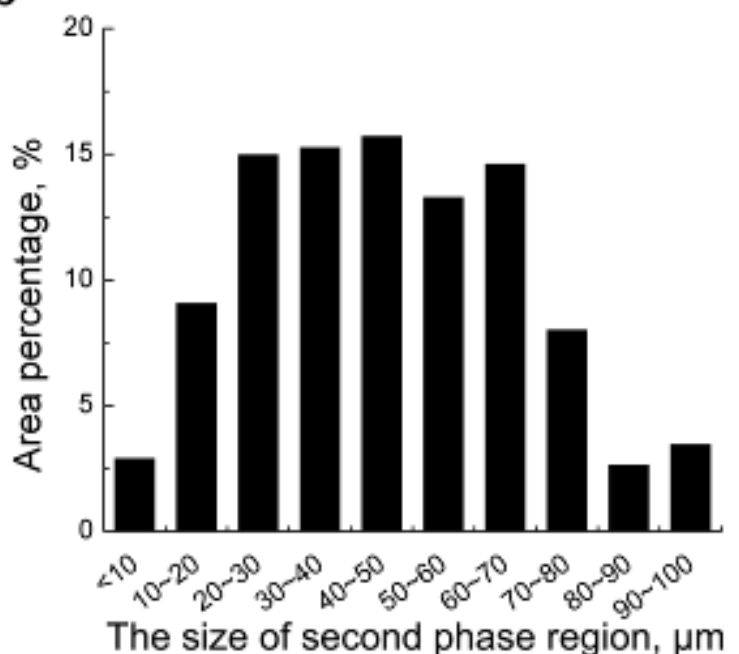

Figure 11. (a) The ferrite grain size distribution and (b) the size distribution of second phase region in the TD 400 sample.

Table 1. Summary of microstructure statistics.

\begin{tabular}{cccccccc}
\hline & & \multicolumn{2}{c}{ Average size, $\mu \mathrm{m}$} & \multicolumn{2}{c}{ Maximum, $\mu \mathrm{m}$} & \multicolumn{2}{c}{ Minimum, $\mu \mathrm{m}$} \\
\cline { 3 - 7 } & Ferrite fraction & $\begin{array}{c}\text { Second } \\
\text { phase region }\end{array}$ & Ferrite & $\begin{array}{c}\text { Second } \\
\text { phase region }\end{array}$ & Ferrite & $\begin{array}{c}\text { Second } \\
\text { phase region }\end{array}$ \\
\hline T 400 & $0.55 \pm 0.06$ & $17 \pm 10$ & $21 \pm 24$ & 51 & 136 & 3 & 3 \\
TD 400 & $0.52 \pm 0.03$ & $13 \pm 7$ & $18 \pm 16$ & 48 & 95 & 3 & 3 \\
\hline
\end{tabular}

Due to its largest product of ultimate tensile strength and total elongation (discussed in Section 3.4 below) and in order to investigate the effect of second phase region size on the RA fraction, the microstructure of TD 400 sample was further studied using EBSD (Fig. 12). In Fig. 12 (a), the second phase region A transformed from one remaining austenite grain after polygonal ferrite formation (referred to as remaining austenite) and the second phase region $\mathrm{B}$ also transformed from one remaining austenite grain, which is demonstrated by the pole figures in Figs. 12 (e) and (f), respectively. As can be seen in Fig. 12 (b), the smaller second phase region $\mathrm{A}$ had a higher RA fraction than that in the larger second phase region $\mathrm{B}$. Most of the RA was distributed along the remaining austenite/polygonal ferrite interfaces (Fig. 12 (b)). Whereas, only a small amount of RA retained inside the second phase regions, i.e. film RA between bainitic ferrite laths and blocky RA between bainite packets (Fig. 12 (b)). The carbon enriched area corresponded to this RA distribution (Fig. 12 (c)). The polygonal ferrite was depleted in carbon compared to the second phase regions. The manganese distribution looks to be homogeneous (Fig. 12 (d)) due to the low diffusion rate of substitutional alloying elements [40] and probably due to a difficulty to detect the small variations in manganese content using this technique. On the other hand, the difference in carbon content in polygonal ferrite and RA was detected (c.f. Figs. 12 (b) and (c)), which is a result of more than an order of magnitude variation in the carbon content between ferrite and RA [32]. 
a

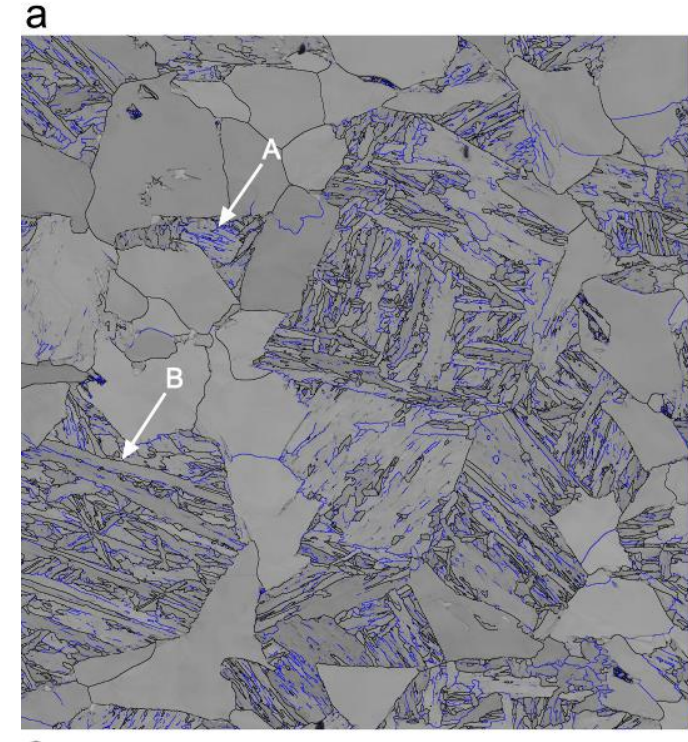

C
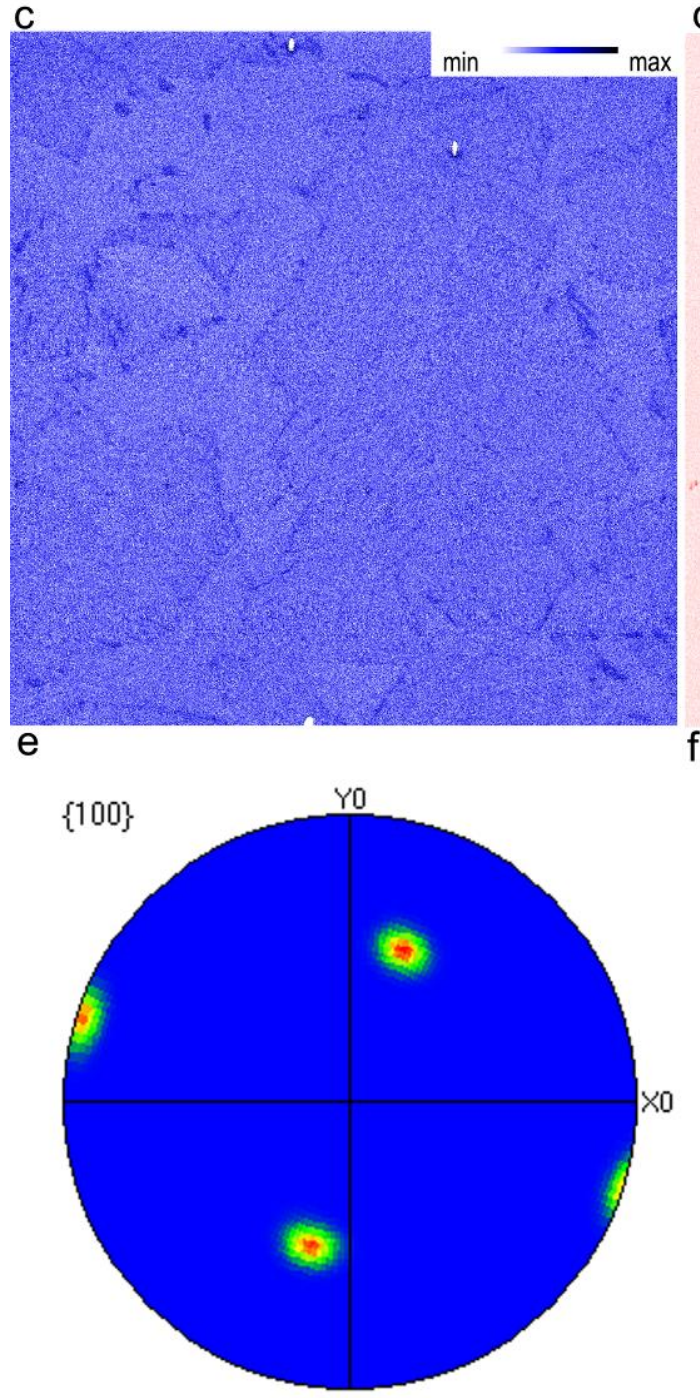

b
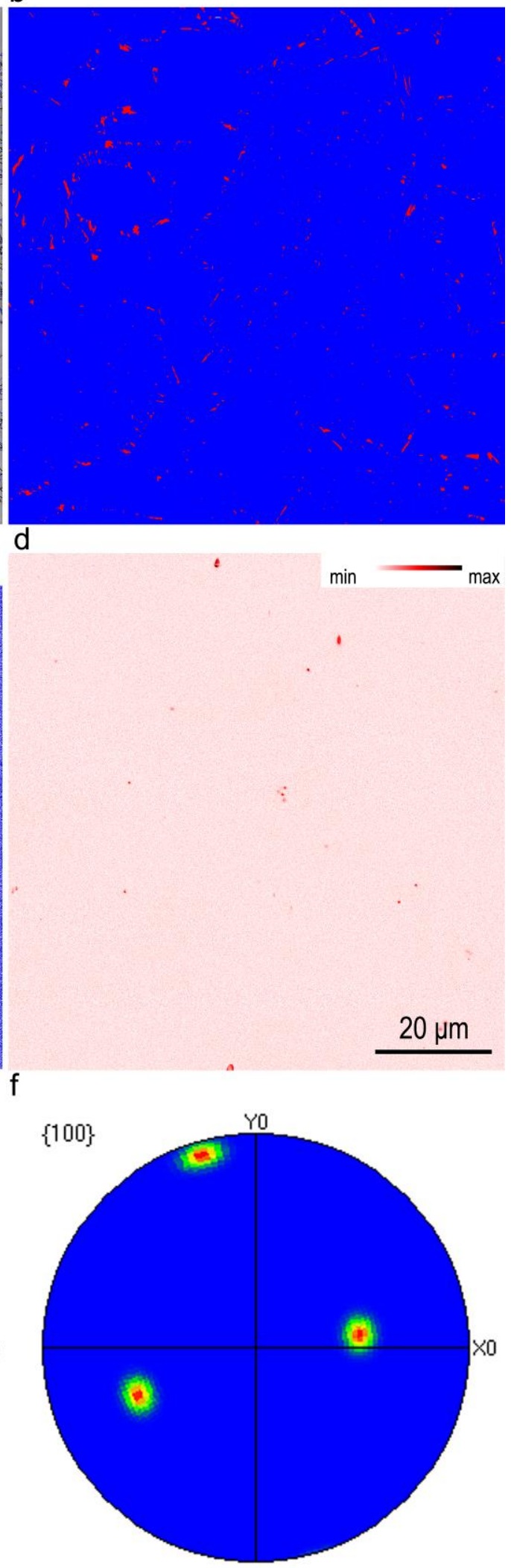

Figure 12. EBSD maps in TD 400 sample of the (a) band contrast with grain boundaries $\left(2^{\circ}<\right.$ low angle grain boundaries $<15^{\circ}=$ blue lines and high angle grain boundaries $\geq 15^{\circ}=$ black lines) and (b) phase distribution $(\mathrm{FCC}=$ red and BCC $=$ blue $)$, EDS elements maps of $(\mathrm{d})$ carbon and (e) manganese, and $(e, f)\{001\}$ pole figures of the experimental orientation spread of the retained austenite grain corresponding to A and B second phase regions marked in (a), respectively. 


\subsection{Mechanical properties}

The engineering stress - engineering strain curves of different thermo-mechanically processed samples are shown in Fig. 13, and corresponding mechanical properties are listed in Table 2. The yield stress (YS) was determined using $0.2 \%$ offset because of continuous yielding behaviour. As expected, TD Q sample had the largest YS and ultimate tensile strength (UTS) with the lowest uniform elongation (UE) and total elongation (TE) due to its ferrite-martensite microstructure. After holding at different IBT temperatures, the TD 400 sample showed the highest UTS of $696 \mathrm{MPa}$ and TE of 0.26 , resulting in the largest product of UTS and TE, namely $18096 \mathrm{MPa} \%$. With an increase or a decrease in the IBT temperature, the UTS and TE decreased.

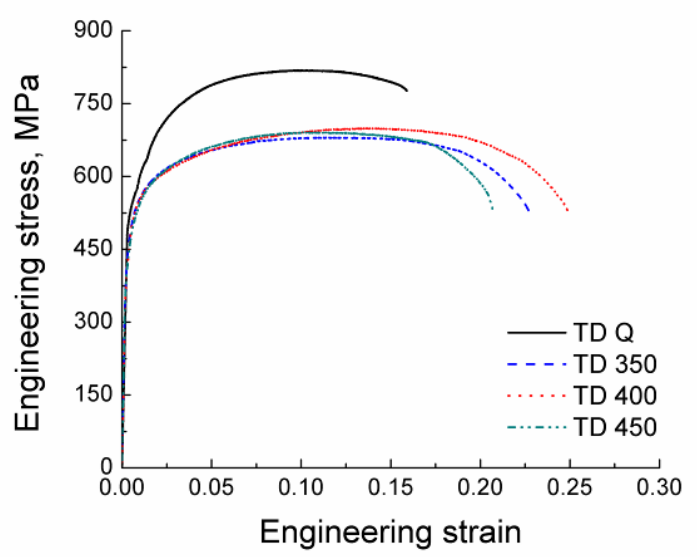

Figure 13. Engineering stress - engineering strain curves of different thermo-mechanically processed samples.

Table 2. Summary of mechanical properties for different processing schedules.

\begin{tabular}{|c|c|c|c|c|c|c|c|}
\hline & Deformation & $\begin{array}{l}\text { Ferrite } \\
\text { fraction }\end{array}$ & $\begin{array}{l}\text { Yield } \\
\text { strength, } \\
\mathrm{MPa}\end{array}$ & $\begin{array}{l}\text { Ultimate } \\
\text { tensile } \\
\text { strength, } \\
\mathrm{MPa}\end{array}$ & $\begin{array}{l}\text { Uniform } \\
\text { elongation }\end{array}$ & $\begin{array}{c}\text { Total } \\
\text { elongation }\end{array}$ & $\begin{array}{c}\text { Product of } \\
\text { ultimate tensile } \\
\text { strength and total } \\
\text { elongation, } \mathrm{MPa} \%\end{array}$ \\
\hline TD Q & & $0.53 \pm 0.05$ & $535 \pm 13$ & $791 \pm 30$ & $0.11 \pm 0.017$ & $0.18 \pm 0.023$ & 14238 \\
\hline TD 350 & & $0.54 \pm 0.01$ & $457 \pm 27$ & $675 \pm 7$ & $0.12 \pm 0.027$ & $0.25 \pm 0.029$ & 16875 \\
\hline TD 400 & $0.41 \pm 0.02$ & $0.52 \pm 0.03$ & $447 \pm 16$ & $696 \pm 6$ & $0.14 \pm 0.002$ & $0.26 \pm 0.008$ & 18096 \\
\hline TD 450 & & $0.56 \pm 0.01$ & $458 \pm 11$ & $688 \pm 5$ & $0.11 \pm 0.020$ & $0.22 \pm 0.013$ & 15136 \\
\hline
\end{tabular}

Compared to the samples produced using dilatometer without deformation, with an increase in the amount of deformation the YS and UTS increased while the UE and TE decreased (Figs. 14(a, b)). In addition, the product of UTS and TE also increased after deformation (Fig. 14(c)). For example, after holding at $400{ }^{\circ} \mathrm{C}$ the UTS increased by $106 \mathrm{MPa}$ while the elongation decreased by 0.01 with an increase in reduction from 0 to 0.41 . As a result, the product of UTS and TE increased from 159350 to $18096 \mathrm{MPa} \%$. Although the difference in thickness of non-deformed $(\sim 1 \mathrm{~mm})$ and deformed samples $(\sim 0.6 \mathrm{~mm})$ was not taken into consideration for its effect on mechanical properties, the ratio of thickness to ferrite grain size 
was around 50 in both conditions. The similarity of this ratio allows to disregard the effect of specimen thickness on the measurements of mechanical properties [41].
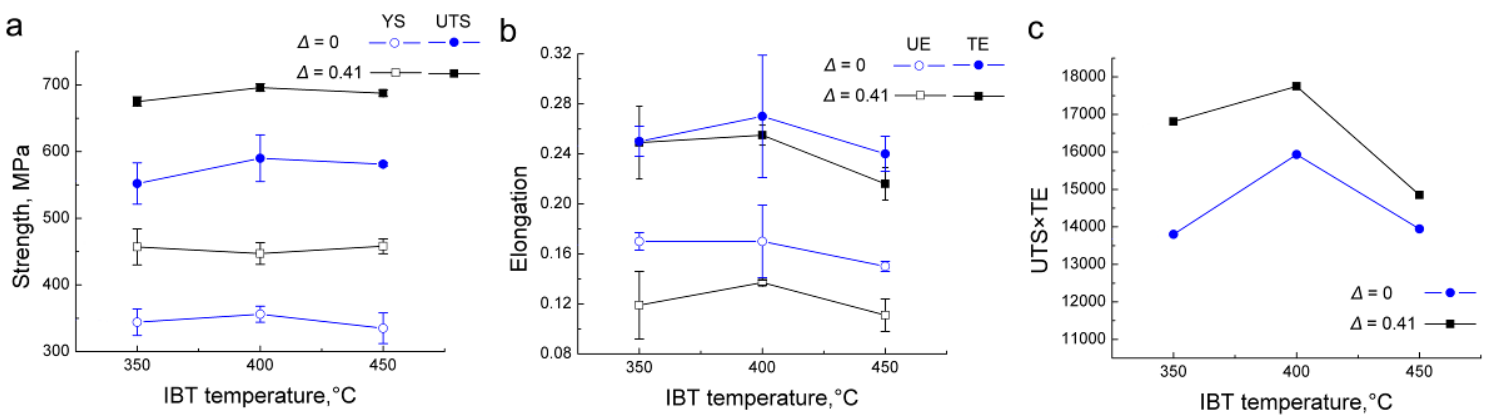

Figure 14. The dependence of (a) yield stress (YS) and ultimate tensile strength (UTS), (b) uniform elongation (UE) and total elongation (TE), and (c) the product of UTS and TE on isothermal bainite transformation temperature and the amount of deformation.

\section{Discussion}

\subsection{Microstructure evolution during thermo-mechanical processing}

A typical microstructure similar to a conventional TRIP steel, comprising polygonal ferrite, bainitic ferrite, granular bainite, RA and martensite, was produced via the strip casting technology simulated in the laboratory. The holding of the samples at $1250{ }^{\circ} \mathrm{C}$ for $300 \mathrm{~s}$ resulted in a prior austenite structure (with an average grain size of $80 \pm 27 \mu \mathrm{m}$ ) similar to that after strip casting. Although the deformation temperature of $1050{ }^{\circ} \mathrm{C}$ was above the nonrecrystallisation temperature $\left(T_{n r}\right)$ for this steel grade (around $950{ }^{\circ} \mathrm{C}[4,33,42]$ ), the dynamic recrystallisation should not have happened, due to the small amount of deformation. This can be supported by a result published in Ref. [31], which stated that completion of the dynamic recrystallisation had required a strain of 0.99 when the PAGS was $120 \mu \mathrm{m}$ and the sample (0.05 C, $0.28 \mathrm{Si}, 0.54 \mathrm{Mn}, 0.01 \mathrm{P}, 0.005 \mathrm{~S}$ and balance $\mathrm{Fe}$, all in wt. \% ) was deformed at $1100{ }^{\circ} \mathrm{C}$ at a strain rate of $1 \mathrm{~s}^{-1}$. However, during cooling of our samples from 1050 to $950{ }^{\circ} \mathrm{C}$, the static recrystallisation took place, leading to the refinement of prior austenite structure. On further cooling to the interrupted cooling temperature of $710{ }^{\circ} \mathrm{C}$, polygonal ferrite predominantly nucleated at prior austenite grain boundaries but not inside the austenite grains, because the dislocation substructures might have recovered due to the high deformation temperature [43]. With an increase in reduction from 0 to 0.41 , the ferrite grain size decreased from $17 \pm 10$ to $13 \pm 7 \mu \mathrm{m}$ (Table 2), due to an increase in the number of ferrite nucleation sites following the prior austenite grain refinement. A small amount of Widmänstatten ferrite was still observed (Figs. 3(a) and 6(a)) probably due to the large PAGS and fast cooling. After $\sim 0.55$ polygonal ferrite formation, the samples were quickly cooled to the IBT temperature in order to avoid pearlite formation [13]. During the holding at IBT temperatures, bainite transformed from austenite and at the same time carbon was rejected to the remaining austenite. During water quenching from the IBT temperature to room temperature, some remaining austenite transformed to martensite and some was preserved as RA, depending on the austenite stability. 


\subsubsection{Effect of isothermal bainite transformation temperature on microstructure evolution}

Holding at $500{ }^{\circ} \mathrm{C}$ was found to be not suitable for TRIP steel production due to pearlite formation (Fig. 10) [34, 39]. With a decrease in IBT temperature from 450 to $350{ }^{\circ} \mathrm{C}$, bainitic ferrite and/or granular bainite were observed in smaller second phase regions (Figs. 4(b) and 6(b)). It could be explained using the thermodynamics. The critical driving force for bainite formation in the steel $(0.19 \mathrm{C}-1.5 \mathrm{Mn}-1.6 \mathrm{Si}-0.2 \mathrm{Mo}$, wt. \%) with similar chemical composition to the studied steel can be expressed as [44]:

$G_{\text {Critical }}=3.64 T-2840$

where $G_{\text {Critical }}$ is the critical driving force for bainite formation $\left(\mathrm{J} \cdot \mathrm{mol}^{-1}\right)$ and $T$ is the holding temperature $\left({ }^{\circ} \mathrm{C}\right)$. Different steels require different coefficients in Eq. (1), whereas, the driving force is proportional to the IBT temperature [12, 45, 46]. With a decrease in IBT temperature, the critical driving force decreases. This means an easier transformation of remaining austenite to bainite with a decrease in temperature.

From the above discussion, the RA fraction in TD 350 sample should be smaller than that in TD 400 sample because more remaining austenite was consumed by bainite formation, which was also reported in Ref. [4]. When the IBT temperature increased to $450{ }^{\circ} \mathrm{C}$, the RA fraction should also be smaller than that in TD 400 sample because cementite was observed by TEM (Figs. 9(c, d)). Cementite formation consumed carbon which should enrich austenite, leading to a decrease in the amount of RA [38, 47, 48].

\subsubsection{Effect of second phase region size on retained austenite retention}

The carbon map (Fig. 12(c)) shows that the carbon content near the interfaces between polygonal ferrite/second phase regions was higher than that inside the second phase regions. In contrast, the manganese content showed a homogenous distribution, despite of few contamination dots or MnS inclusions (Fig. 12(d)). These phenomena could be explained via thermodynamics. The volume diffusivities of manganese and carbon in austenite are respectively expressed as following $[32,49]$ :

$$
\begin{aligned}
& D_{l}^{M n}=1.78 \times 10^{-5} \exp (-264000 / R T) \\
& D_{l}^{C}=1.75 \times 10^{-5} \exp (-143320 / R T)
\end{aligned}
$$

where $R$ is the gas constant $\left(8.314 \mathrm{~J} \cdot \mathrm{mol}^{-1} \cdot \mathrm{K}^{-1}\right)$ and $T$ is the temperature in Kelvin. The diffusion distance $(d)$ is calculated as follows [47]:

$d=\sqrt{D t}$

where $t$ is the holding time in seconds. The austenite-to-ferrite transformation temperature $\left(\mathrm{Ar}_{3}\right)$ is around $810{ }^{\circ} \mathrm{C}$ according to a TRIP steel with similar chemical compositions and a PAGS between 45 and $80 \mu \mathrm{m}$ [34]. It took $10 \mathrm{~s}$ to cool the sample at $10 \mathrm{Ks}^{-1}$ from the assumed $\mathrm{Ar}_{3}$ to the accelerated cooling temperature of $710{ }^{\circ} \mathrm{C}$; thus, the holding time $t$ for 
element diffusion can be set as the maximum of $10 \mathrm{~s}$. If a medium value of $760{ }^{\circ} \mathrm{C}$ is chosen as the diffusion temperature $T$ and the time is set between 5 and $10 \mathrm{~s}$, the calculated diffusion distances of carbon and manganese would be $2.2-3.1 \mu \mathrm{m}$ and $2.0-2.8 \mathrm{~nm}$, respectively. This carbon diffusion range resulted in a layer of high carbon content adjacent to the remaining austenite grain boundaries (Fig. 12(c)), which was also demonstrated in Refs. [47, 50]. Manganese diffused much shorter distances which led to its homogenous distribution compared to carbon (c.f. Figs. 12(c) and (d)).

A higher carbon content near the remaining austenite grain boundaries, compared to that inside the remaining austenite grains, led to more RA grains adjacent to the polygonal ferrite/second phase region interfaces after quenching to room temperature from the IBT temperatures. In addition, some tiny RA grains were inside the second phase region due to the carbon enrichment during the bainite formation (Fig. 12(b)). As a result, the RA fraction in a larger second phase region was lower than that in a smaller one (Fig. 12 (b)). This corresponds to Hanzaki et. al. who also showed the RA fraction decreased from 0.071 to 0.051 when PAGS increased from 45 to $350 \mu \mathrm{m}$ [17].

The second phase region was only refined from $21 \pm 24$ to $18 \pm 16 \mu \mathrm{m}$ with an increase in reduction from 0 to 0.41 . Based on the above discussion, it means that the RA fraction after deformation may only change marginally in the studied TRIP steel; the RA fraction in the non-deformed samples was reported to be between 0.02 and 0.05 [28].

\subsection{Effect of isothermal bainite holding temperature and deformation on mechanical properties}

As shown in Fig. 14, the combination of strength and ductility after holding at $400{ }^{\circ} \mathrm{C}$ was the highest, whether the deformation was applied or not. Without deformation, the best combination of properties after holding at $400{ }^{\circ} \mathrm{C}$ was ascribed to the highest RA fraction in the previous study [28]. This phenomenon after holding at different IBT temperatures was reported by many researchers $[1,51,52]$. It was also explained by the largest fraction of RA with suitable carbon content after holding at $400{ }^{\circ} \mathrm{C}[1,51,52]$. Based on the discussion in Section 4.1.1, it is probable that the largest RA fraction was also obtained in TD 400 sample and this was responsible for the best combination of strength and ductility.

The strengthening with deformation, observed in this study (Fig. 14), could be predominantly explained by grain refinement and dislocation strengthening. Due to the same processing condition for polygonal ferrite formation, all three samples (TD 350, TD 400 and TD 450) had similar average polygonal ferrite grain sizes. Besides, the dislocation densities for TD 350, TD 400 and TD 450 samples were similar because of low holding temperatures, namely $10.4 \pm 0.75 \times 10^{13}, 9.8 \pm 0.56 \times 10^{13}$ and $9.4 \pm 0.67 \times 10^{13} \mathrm{~m}^{-2}$, respectively, although the dislocation recovery was different due to different IBT temperatures. Thus, as a representative example, the TD 400 sample was used for the analysis of the strengthening mechanism. After holding at $400{ }^{\circ} \mathrm{C}$, with an increase in reduction from 0 to 0.41 , the YS and UTS respectively increased by 91 and $106 \mathrm{MPa}$, while the TE decreased by 0.01 . This resulted in an increase in the product of UTS and TE, which indicated an increase in formability [53]. Three aspects 
should be considered for the strengthening. First of all, after deformation the ferrite grain size decreased from $17 \pm 10$ to $13 \pm 7 \mu \mathrm{m}$, which increased the grain refinement contribution to YS by $52 \mathrm{MPa}$ according to the Hall - Petch equation [54]:

$$
\sigma=\sigma_{0}+k d^{-1 / 2}
$$

where the $\sigma_{0}$ and $k$ are material constants, and $k$ is equal to $1500 \mathrm{MPa} \cdot \mu \mathrm{m}^{-1 / 2}$ based on 0.45 fraction of the second phases [55]. Secondly, the deformation increased the dislocation density in the polygonal ferrite. As shown in Fig. 15, the dislocation density in the TD 400 sample $\left(9.8 \pm 0.56 \times 10^{13} \mathrm{~m}^{-2}\right)$ was higher than that in the T 400 sample $\left(5.1 \pm 0.42 \times 10^{13} \mathrm{~m}^{-2}\right)$. This increase in dislocation density accounts for $58 \mathrm{MPa}$ increase in YS according to the Bailey - Hirsch relationship [56]:

$$
\sigma_{d i s}=M \alpha G b \rho^{1 / 2}
$$

where $M$ is the Taylor factor ( $M=2.75$ for random textured bcc metals), $\alpha$ is a constant ( $\alpha=$ 0.38 in bcc iron), $G$ is shear modulus ( $G=81.6 \mathrm{GPa}), b$ is the Burgers vector $(b=0.248 \mathrm{~nm})$ and $\rho$ is the average dislocation density in polygonal ferrite. Thirdly, the size of the second phase region was refined from $21 \pm 24$ to $18 \pm 16 \mu \mathrm{m}$, which also could increase the strength: the smaller second phase regions had more interfaces with polygonal ferrite, resulting in a local increase in the dislocation density in ferrite, and a more pronounced interaction between the polygonal ferrite and second phases during deformation [4]. Thus, the grain refinement and dislocation strengthening was ascribed to be the main reason for the improvement of mechanical properties after deformation. To this end, the variation in the RA contribution to strength is expected to be low due to a marginal change in RA fraction after deformation (as discussed in Section 4.1.2).

a

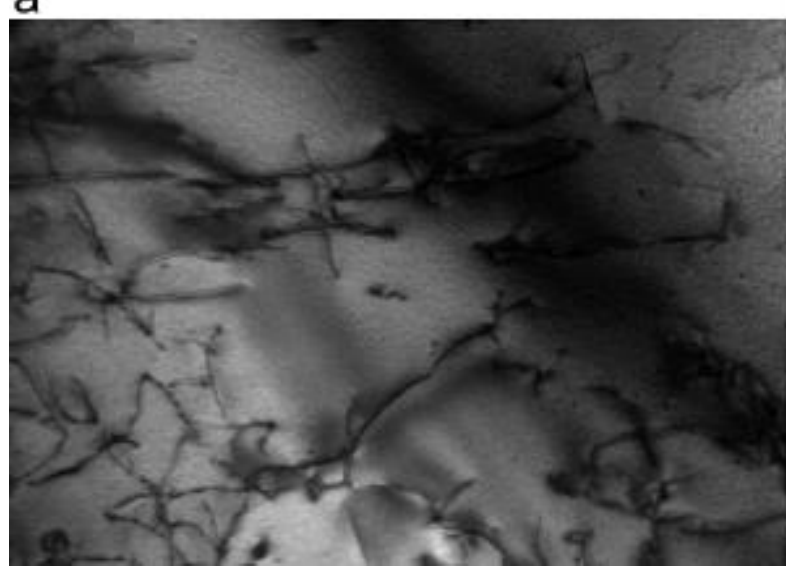

b

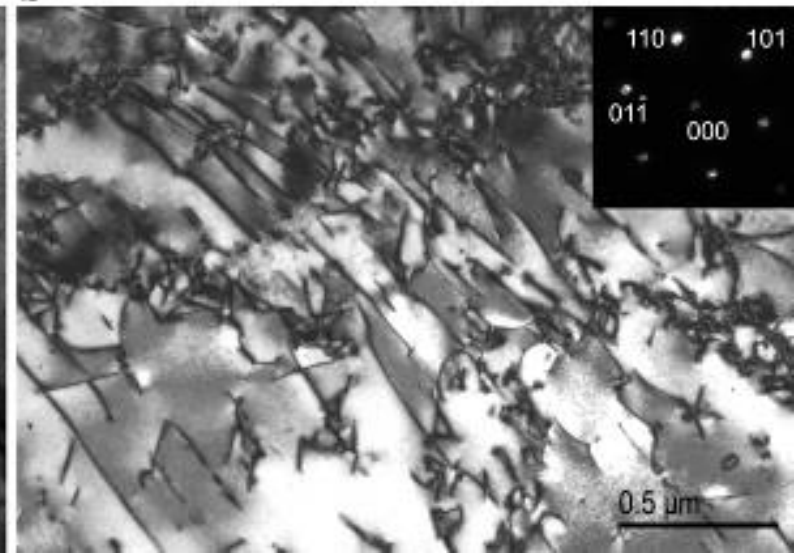

Figure 15. Dislocations in polygonal ferrite of (a) T 400 and (b) TD 400 samples. The zone axis in (a, b) is $[\overline{1} 11]_{\alpha}$.

The mechanical properties of the investigated TRIP steel produced by strip casting were compared with the ones commercially produced using hot rolling [57]. As can be seen in Fig. 16 , the studied steels treated without deformation, especially the T 400 sample, exhibited the 
comparable mechanical properties with TRIP 590. The studied deformed TRIP steels, especially for the TD 400 sample, had comparable mechanical properties with TRIP 690. In the future, the mechanical properties can be further improved by deformation in the nonrecrystallisation temperature region and micro-alloying with additions of molybdenum, vanadium or niobium. Alternatively, the cold rolling and annealing following the strip casting could be another route to improve the mechanical properties of TRIP steel.

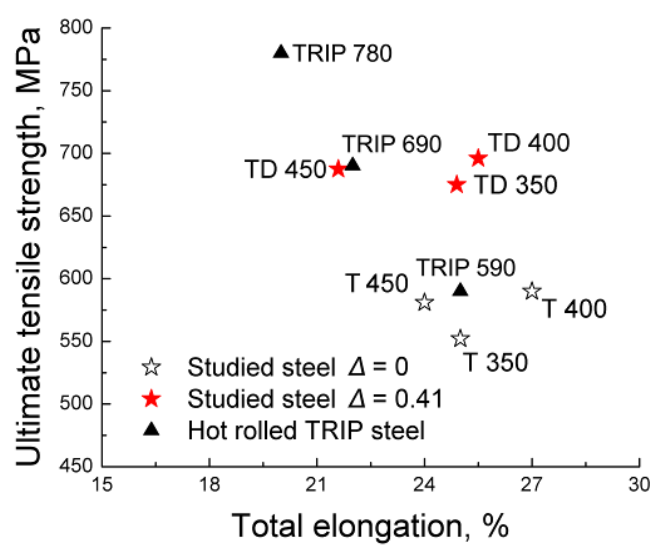

Figure 16. Comparison of mechanical properties for the studied steels and hot rolled TRIP steels from Nippon Steel \& Sumitomo Metal Corporation's brochure [57].

\section{Conclusions}

A conventional TRIP steel $(0.17 \mathrm{C}-1.52 \mathrm{Si}-1.61 \mathrm{Mn}-0.03 \mathrm{Al}$ wt. \%) was produced using the strip casting technique simulated in the laboratory. The conclusions of the present study are as follows:

(1) A typical microstructure of TRIP steels, consisting of $\sim 0.55$ fraction of polygonal ferrite with bainitic ferrite, granular bainite, RA and martensite, was obtained. Noticeably, a very little amount of Widmänstatten ferrite was also observed.

(2) The distribution of the RA was non-uniform. It was predominantly located at the interfaces between the polygonal ferrite and second phase regions, while some RA grains, in the form of films and blocky islands, located inside the second phase regions. These RA locations corresponded to the carbon enriched areas identified using EDS.

(3) Larger second phase regions had a lower RA fraction than the smaller second phase regions.

(4) As a result of deformation, the ultimate tensile strength increased by $106 \mathrm{MPa}$ while the total elongation decreased by 0.01 after holding at $400{ }^{\circ} \mathrm{C}$. The strengthening was mainly ascribed to the microstructure refinement. 
(5) The mechanical properties of studied TRIP steels produced using simulated deformation during strip casting were comparable to the industrially manufactured TRIP 690 steel.

\section{Acknowledgements:}

This project was supported by the Australian Research Council (DP130101887). The JEOL JSM-7001F FEG-SEM and JEOL JEM-ARM200F were funded by the Australian Research Council (LE0882613 and LE120100104, respectively). The authors thank Dr. A.A. Gazder and Dr. A.A. Saleh University of Wollongong for modification of the tensile stage and EBSD mapping, respectively. The authors also thank Associate Professor N.E. Stanford for casting of the flat samples at Deakin University.

\section{References:}

[1] A. Mertens, E.M. Bellhouse, J.R. McDermid, Mater. Sci. Eng. A 608 (2014) 249-257.

[2] R. Kuziak, R. Kawalla, S. Waengler, Arch. Civ. Mech. Eng. 8 (2008) 103-117.

[3] A.F. Mark, X. Wang, E. Essadiqi, J.D. Embury, J.D. Boyd, Mater. Sci. Eng. A 576 (2013) 108-117.

[4] R. Ranjan, H. Beladi, S.B. Singh, P.D. Hodgson, Metall. Mater. Trans. A 46A (2015) 3232-3247.

[5] H.X. Yin, A.M. Zhao, Z.Z. Zhao, X. Li, S.J. Li, H.J. Hu, W.G. Xia, Int. J. Min. Metall. Mater. 22 (2015) 262-271.

[6] E.V. Pereloma, A.A. Gazder, I.B. Timokhina, Mater. Sci. Forum 738 (2013) 212-216.

[7] E.V. Pereloma, H. Beladi, L. Zhang, I.B. Timokhina, Metall. Mater. Tran. A 43 (2012) 3958-3971.

[8] I.B. Timokhina, P. Hodgson, E.V. Pereloma, Metall. Mater. Tran. A 35 (2004) 2331-2341.

[9] E.V. Pereloma, P. Hodgson, Mater. Sci. Eng. A 251 (1998) 30-39.

[10] K. Sugimoto, N. Usui, M. Kobayashi, S. Hashimoto, ISIJ Int. 32 (1992) 1311-1318.

[11] E.V. Pereloma, I.B. Timokhina, P. Hodgson, Mater. Sci. Eng. A 273 (1999) 448-452.

[12] S. Li, R. Zhu, I. Karaman, R. Arroyave, Acta Mater. 61 (2013) 2884-2894.

[13] S. Li, R. Zhu, I. Karaman, R. Arroyave, Acta Mater. 60 (2012) 6120-6130.

[14] P.J. Jacques, J. Ladriere, F. Delannay, Metall. Mater. Trans. A 32 (2001) 2759-2768.

[15] R. Nooning Jr, C. Killmore, H. Kaul, A. Phillips, D. Edelman, P. Campbell, J. Williams, in: Proceedings of the International Conference on Microalloyed Steels, 2007, pp. 16-19.

[16] K. Mukunthan, P.D. Hodgson, L. Strezov, N. Stanford, ISIJ Int. 53 (2013) 2152-2159.

[17] A.Z. Hanzaki, P.D. Hodgson, S. Yue, Metall. Mater. Trans. A 28 (1997) 2405-2414.

[18] A.B. Cota, C.A.M. Lacerda, F.L.G. Oliveira, F.A. Machado, F.G.D. Araujo, Scr. Mater. 51 (2004) 721-725.

[19] M. Arribas, B. Lopez, J.M. Rodriguez-Ibabe, Mater. Sci. Eng. A 485 (2008) 383-394.

[20] S. Kang, S. Yoon, S.J. Lee, ISIJ Int. 54 (2014) 997-999.

[21] S.J. Lee, J.S. Park, Y.K. Lee, Scr. Mater. 59 (2008) 87-90.

[22] M. Umemoto, K. Horiuchi, I. Tamura, Tetsu-to-Hagane 22 (1982) 854-861.

[23] S. Ge, M. Isac, R.I.L. Guthrie, ISIJ Int. 52 (2012) 2109-2122.

[24] N. Zapuskalov, ISIJ Int. 43 (2003) 1115-1127.

[25] M. Daamen, C. Haase, J. Dierdorf, D.A. Molodov, G. Hirt, Mater. Sci. Eng. A 627 (2015) 72-81.

[26] Z.P. Xiong, A.G. Kostryzhev, N.E. Stanford, E.V. Pereloma, Mater. Sci. Eng. A 651 (2016) 291-305.

[27] Z.P. Xiong, A.G. Kostryzhev, N.E. Stanford, E.V. Pereloma, Mater. Des. 88 (2015) 537-549.

[28] Z.P. Xiong, A.G. Kostryzhev, A.A. Saleh, L. Chen, E.V. Pereloma, Mater. Sci. Eng. A 664 (2016) 26-42.

[29] T. Dorin, N. Stanford, A. Taylor, P. Hodgson, Metall. Mater. Tran. A 46 (2015) 5561-5571.

[30] L. Strezov, J. Herbertson, ISIJ Int. 38 (1998) 959-966.

[31] H.Y. Gao, Z.X. Xie, Y. Yu, Y. Fang, J. Wang, B.D. Sun, ISIJ Int. 49 (2009) 546-552.

[32] Z.D. Li, Z.G. Yang, C. Zhang, Z.Q. Liu, Mater. Sci. Eng. 527 (2010) 4406-4411.

[33] M. El Mehtedi, S. Spinarelli, J. Zrnik, Metall. Ital. (2010) 5-10.

[34] A. Zarei-Hanzaki, S. Yue, ISIJ Int. 37 (1997) 583-589.

[35] S.J. Kim, C.G. Lee, I. Choi, S. Lee, Metall. Mater. Trans. A 32 (2001) 505-514.

[36] A.A. Gazder, F. Al-Harbi, H.T. Spanke, D.R. Mitchell, E.V. Pereloma, Ultramicroscopy 147 (2014) 114132.

[37] M. Takahashi, H. Bhadeshia, Mater. Trans. JIM 32 (1991) 689-696.

[38] E.V. Pereloma, I.B. Timokhina, M.K. Miller, P.D. Hodgson, Acta Mater. 55 (2007) 2587-2598.

[39] S.M.K. Hosseini, A. Zaeri-Hanzaki, S. Yue, Mater. Sci. Eng. A 618 (2014) 63-70.

[40] S. Yoon, S.J. Lee, ISIJ Int. 54 (2014) 1453-1455. 
[41] J. An, Y.F. Wang, Q.Y. Wang, W.Q. Cao, C.X. Huang, Mater. Sci. Eng. A 651 (2016) 1-7.

[42] S.M.K. Hosseini, A. Zarei-Hanzaki, E. Essadiqi, S. Yue, Mater. Sci. Technol. Lond. 24 (2008) 1354-1361.

[43] K. Park, M. Nishiyama, N. Nakada, T. Tsuchiyama, S. Takaki, Mater. Sci. Eng. A 604 (2014) 135-141.

[44] F. Fazeli, M. Militzer, ISIJ Int. 52 (2012) 650-658.

[45] F. Fazeli, T. Jia, M. Militzer, Solid State Phenom. 172-174 (2011) 1183-1188.

[46] D. Gaude-Fugarolas, P.J. Jacques, ISIJ Int. 46 (2006) 712-717.

[47] F. Fazeli, X. Wang, ISIJ Int. 47 (2007) 1341-1350.

[48] F.G. Caballero, M.K. Miller, S.S. Babu, C. Garcia-Mateo, Acta Mater. 55 (2007) 381-390.

[49] M. Kumar, R. Sasikumar, P.K. Nair, Acta Mater. 46 (1998) 6291-6303.

[50] N.M. Xiao, M.M. Tong, Y.J. Lan, D.Z. Li, Y.Y. Li, Acta Mater. 54 (2006) 1265-1278.

[51] Y. Zhao, Q. Yan, L. Chen, X. Yuan, Acta Metall. Sin. 27 (2014) 389-394.

[52] I.B. Timokhina, E.V. Pereloma, P.D. Hodgson, Mater. Sci. Technol. Lond. 17 (2001) 135-140.

[53] Z.Z. Zhao, T.T. Tong, J.H. Liang, H.X. Yin, A.M. Zhao, D. Tang, Mater. Sci. Eng. A 618 (2014) 182-188.

[54] S. Takaki, Mater. Sci. Forum 654-656 (2010) 11-16.

[55] P.H. Chang, A.G. Preban, Acta Metall. 33 (1985) 897-903.

[56] N. Kamikawa, K. Sato, G. Miyamoto, M. Murayama, N. Sekido, K. Tsuzaki, T. Furuhara, Acta Mater. 83 (2015) 383-396.

[57] http://www.nssmc.com/en/. 